\title{
A Mountain-Scale Model for Characterizing Unsaturated Flow and Transport in Fractured Tuffs of Yucca Mountain
}

\author{
Yu-Shu Wu*@ , Guoping Lu, Keni Zhang, and G. S. Bodvarsson
}

\begin{abstract}
This paper presents a large-scale modeling study characterizing fluid flow and tracer transport in the unsaturated zone of Yucca Mountain, Nevada, the proposed underground repository site for storing high-level radioactive waste. The modeling study is conducted using a three-dimensional numerical model, which incorporates a wide variety of field data and takes into account the coupled processes of flow and transport in Yucca Mountain's highly heterogeneous, unsaturated, fractured porous rock. The modeling approach is based on a dual-continuum formulation. Using different conceptual models of unsaturated flow, various scenarios of current and future climate conditions and their effects on the unsaturated zone are evaluated to aid in the assessment of the repository's system performance. These models are calibrated against field-measured data. Model-predicted flow and transport processes under current and future climates are discussed.
\end{abstract}

\footnotetext{
@ Yu-Shu Wu, Guoping Lu, Keni Zhang, and G. S. Bodvarsson, Earth Sciences Division, Lawrence Berkeley National Laboratory, Berkeley, CA, 94720, USA. *Corresponding author (YSWu@lbl.gov)
} 


\section{INTRODUCTION}

In the past two decades, significant progress has been made in characterizing flow and transport processes in fractured rock of the unsaturated zone (UZ) of the highly heterogeneous, fractured tuff at Yucca Mountain, Nevada, the proposed permanent subsurface repository for storing high-level radioactive waste. Since the 1980s, extensive field studies have been performed and many types of data have been collected to investigate flow and transport processes. Based on these field data, a number of numerical models have been developed for evaluating UZ hydrological conditions. Studies before the 1990s primarily used one- and two-dimensional models for understanding basic flow and transport behavior (Rulon et al., 1986; Tsang and Pruess, 1987). In the 1990s, Wittwer and co-workers (1992 and 1995) started an effort to develop a three-dimensional (3-D) model that incorporated many geological and hydrological complexities. Ahlers et al. (1995) and Wu et al. (1997) continued the work of developing the site-scale UZ model, but with increased spatial resolution and incorporating more physical processes, such as gas and heat flow. Since then, more comprehensive model calibrations and studies, using mountain-scale numerical models, have been made to investigate fluid flow and radionuclide transport processes within the Yucca Mountain UZ (e.g., Viswanathan et al., 1998; Ahlers et al., 1999; Bandurraga and Bodvarsson, 1999; Wu et al., 1999a; 1999b; 2002a; 2002b; Robinson et al., 2003).

The modeling studies of this paper represent our continuing effort in development and application of the mountain-scale UZ flow model (Wu et al., 2003), which is in turn based on the analysis and results of the above-referenced work (as well as many other studies). Building upon our previous investigations (Wu et al., 1999a; 1999b; 2002a), this work presents more comprehensive 3-D model calibrations using field-measured pore- 
water chloride data, in addition to moisture and perched-water data. Moreover, the model we present here uses both a much more refined grid and special connections between the gridblocks of rock matrix and fractures (at the interfaces between a few selected hydrogeologic units) to represent the UZ system. Specifically, the current repository design, updated field data, and rock properties are incorporated into this model.

The primary objective of this paper is to summarize the features of the current mountain-scale flow and transport model. First, we discuss how the model is calibrated against saturation, water potential, perched water, and chloride data. Second, we analyze flow behavior and patterns in the Yucca Mountain UZ system. As application examples, we use the model to simulate ambient hydrological conditions for use in predicting the system response to future climate conditions. The emphasis is on how to quantify moisture flow through the UZ under present-day and estimated future climate scenarios, and to estimate groundwater travel times from the proposed repository level to the water table.

\section{MODEL DESCRIPTION}

\section{Geological Setting and Model Grid}

The aerial domain of the mountain-scale UZ flow model encompasses approximately $40 \mathrm{~km}^{2}$ of the Yucca Mountain area (Figure 1a). As shown in Figures $1 \mathrm{~b}$ and $1 \mathrm{c}$, the $\mathrm{UZ}$ is between 500 and $700 \mathrm{~m}$ thick and overlies a relatively flat water table. Yucca Mountain is a structurally complex geological system of Tertiary volcanic rocks, a heterogeneous environment of layered, anisotropic, fractured tuffs (Scott and Bonk, 1984). The primary geological formations found at Yucca Mountain (from the land surface down), as shown in Figures $1 \mathrm{~b}$ and 1c, consist of the Tiva Canyon, Yucca Mountain, Pah Canyon, and the Topopah Spring tuffs of the Paintbrush Group. 
Underlying these units are the Calico Hills Formation and the Prow Pass, Bullfrog, and Tram Tuffs of the Crater Flat Group (Buesch et al., 1995). These geological formations have been reorganized into hydrogeologic units based primarily on the degree of welding (Montazer and Wilson 1984): the Tiva Canyon welded (TCw) hydrogeologic unit; the Paintbrush nonwelded unit (PTn), consisting primarily of the Yucca Mountain and Pah Canyon members and their bedded tuffs; the Topopah Spring welded (TSw) unit; the Calico Hills nonwelded (CHn) unit; and the Crater Flat undifferentiated $(\mathrm{CFu})$ unit.

The 3-D mountain-scale UZ flow model domain, as well as the unstructured numerical grid for this study, is shown in plan view in Figure 1a. The UZ flow model grid is primarily designed for the purpose of model calibrations and investigation of UZ flow behavior. This 3-D UZ flow model grid uses a refined mesh in the vicinity of the proposed repository, located near the center of the model domain, covering the region from the Solitario Canyon fault to the Ghost Dance fault from west to east, and from the Pagany Wash fault to borehole UZ\#16 from north to south. Also shown in Figure 1a are the locations of several boreholes used in model calibrations and analyses. The model domain is selected to focus on the study area of the proposed repository and to investigate the effects of different infiltration scenarios and major faults on moisture flow around and below the proposed repository. In the UZ flow model grid, faults are represented by vertical or inclined $30 \mathrm{~m}$ wide zones (Figures $1 \mathrm{~b}$ and 1c).

The UZ flow model grid, as shown in Figures 1a, 1b, and 1c, has 2,042 columns (or gridblocks per layer) of both fracture and matrix continua, and averages 59 computational grid layers in the vertical direction, resulting in approximately 250,000 gridblocks and 1,000,000 connections in a dual-permeability grid. This model grid is more refined than those for previous mountain-scale UZ models (e.g., Wu et al., 2002a). 


\section{Modeling Approach}

Model calibration and simulation results were carried out using the TOUGH2 and T2R3D codes (Pruess, 1991; Wu and Pruess, 2000). In these two TOUGH2-family codes, the integral finite-difference scheme is used for spatial discretization, and the time discretization is carried out with a backward, first-order, finite-difference scheme. The resulting discrete nonlinear algebraic equations for describing mass (or component) and/or energy conservation are written in a residual form and solved using the Newton/Raphson iteration with an iterative linear solver. At each time step, iteration is continued until convergence is reached for a given time when the residuals at all gridblocks are decreased to a preset convergence tolerance.

In particular, UZ flow simulations in this study were performed using the unsaturated flow module (EOS9) of the TOUGH2 code, which solves Richards' equation. Note that the moisture movement in the current UZ system is approximated at quasisteady or steady-state condition. Therefore, each flow simulation is run to steady state and steady-state solutions are further confirmed using a global mass-balance check (i.e., total water recharge or inflow from the surface boundary is balanced by outflow out of the model bottom water table boundary). Furthermore, tracer transport and chloride studies were performed under steady-state UZ flow conditions using a decoupled transport module of the $\mathrm{T} 2 \mathrm{R} 3 \mathrm{D}$ for modeling advective and dispersive transport processes through fractured tuffs. Steady-state UZ flow fields generated by the flow calculations were used as direct input for transport modeling.

In evaluating fluid flow and transport in unsaturated fractured tuffs, fracturematrix interactions are generally handled by using a dual-permeability concept. The dualpermeability methodology considers global flow and transport occurring not only between fractures but also between matrix gridblocks. In this approach, the rock-volume 
domain is represented by two overlapping (yet interacting) fracture and matrix continua, and local fracture-matrix flow and transport are approximated as a quasi-steady state. The traditional dual-permeability concept is modified using an active fracture model (Liu et al., 1998) to represent the fingering effects of flow through fractures and to limit flow into the matrix system. Furthermore, the dual-permeability grid is modified by having additional global fracture-matrix connections at the TCw-PTn and PTn-TSw interfaces and at boundaries of vitric units. Vitric units in $\mathrm{CHn}$ are handled as single-porosity matrix. Adding global fracture and matrix connections for these single-porosity matrix blocks provides physical links for possible fracture-matrix flow transitions that may occur across the domain boundaries of single- and dual-continuum media. Therefore, the modeling approach for handling fractured tuffs is actually a physically based, hybrid dual-permeability model, with a combination of dual-continuum and single-porosity meshes for spatial discretization of the UZ model domain.

\section{Boundary Conditions}

For the UZ flow model, the ground surface of the mountain (or the tuff-alluvium contact in areas of significant alluvial cover) is taken as the top model boundary; the water table is treated as the bottom model boundary. Both the top and bottom boundaries are treated as Dirichlet-type conditions with specified pressure or saturation values. For flow simulations using the Richards' equation with the EOS9 module, both surface and bottom model boundaries are considered as unsaturated, with the bottom boundary at nearly fully saturated conditions. Therefore, only saturation needs to be specified, which is equivalent to fixed pressure conditions along the bottom model boundary. Surface infiltration is applied using a source term in the fracture gridblocks within the second grid layer from the top, because the first layer is assigned as a Dirichlet-type boundary fixed at 
a constant pressure or saturation to represent average atmospheric conditions at the mountain. All lateral boundaries, as shown in Figure 1, are treated as no-flow (closed) boundaries. Note that flow in the UZ is predominantly vertical in most hydrogeological units as well as through faults, and thus no-flow conditions at lateral boundaries will provide good approximations. In addition, no-flow boundaries should have little effect on moisture flow and radionuclide transport within or near the repository area (at the center of the model domain as the focus of the current study), because these lateral boundaries are either far away from the repository or separated by vertical faults (Figures 1a, 1b, and 1c).

Net infiltration from precipitation at the land surface is the major control on overall hydrological and thermal-hydrological conditions within the Yucca Mountain UZ. To cover the various possible scenarios and uncertainties of future climates at Yucca Mountain, we have incorporated a total of nine net infiltration maps into the model, provided by U.S. Geological Survey (USGS) scientists (Hevesi and Flint, 2000). These infiltration maps include three climate scenarios: present-day (modern), monsoon, and glacial transition, each of which consists of lower-bound, mean, and upper-bound rates. This results in the nine infiltration rates, as summarized in Table 1, which shows average net recharge values over the model domain.

As shown in Table 1, the average rate for the present-day, mean infiltration over the UZ flow model domain is $4.4 \mathrm{~mm} / \mathrm{yr}$, which is considered as the base-case, scenario. The use of the lower- and upper-bound infiltration values is intended to cover the uncertainties (associated with the infiltration models). The two climate scenarios, the monsoon and glacial transition periods, are used to account for possible higher precipitation and infiltration conditions in the future at Yucca Mountain. Note that the glacial transition period has higher infiltration rates than its corresponding present-day 
and monsoon periods, except for the lower-bound infiltration case of the monsoon period. In this paper, both present-day and future infiltration scenarios are considered to be constant in simulation times, and no transient effects are taken into account. Table 1 also shows that each of the nine infiltration maps corresponds to two simulation scenarios, one called "base case" and the other "alternative." The difference between the base case and alternative case is in the use of different rock properties for the PTn unit, as discussed below.

A plan view of the spatial distribution of the present-day mean infiltration maps, as interpolated onto the UZ flow model grid, is shown in Figure 2. The figure shows patterns of flux distributions with higher infiltration rates in the northern part of the model domain and along the mountain ridge east of the Solitario Canyon fault from south to north.

\section{Model Parameters}

With the dual-continuum modeling approaches used in this modeling study, two sets of properties (such as relative permeability and capillary pressure curves), along with other intrinsic properties (such as porosity, permeability, density, fracture geometric parameters, and transport properties), are needed for the two media of the fracture and matrix systems. In our modeling study, the van Genuchten model of relative permeability and capillary pressure functions (van Genuchten, 1980) are adopted to describe variably saturated flow in both the fracture and matrix continua. Therefore, the basic rock and flow parameters used for each model layer or subunit include (1) fracture properties (frequency, spacing, porosity, permeability, van Genuchten $\alpha$ and $m$ parameters, residual saturation, and fracture-matrix interface area); (2) matrix properties (porosity, permeability, the van Genuchten $\alpha$ and $m$ parameters, and residual saturation); (3) 
transport properties (grain density, diffusion, adsorption, and tortuosity coefficients); and

(4) fault properties (porosity, matrix and fracture permeabilities, active fracture-matrix interface area) for each of the major hydrogeologic units.

Initial guesses of the input parameters for rock and flow properties of each model layer, as well as for fault-fracture properties, are taken from parameters that are either measured or estimated using a 1-D inversion modeling approach (Liu et al., 2003a and 2003b). Then, 1-D model estimated properties are calibrated and modified through a series of 3-D model calibrations, using field-measured moisture content, perched water, and chloride data (Wu et al., 2003).

\section{MODEL CALIBRATIONS}

Model calibration has been a critical step in developing the mountain-scale UZ flow model of Yucca Mountain, as an important, iterative process of model development and verification. Past modeling experiences (e.g., Wu et al., 1999a, 1999b and 2002) have shown that we cannot simply take field- and laboratory-measured parameters or 1-D model estimated properties as direct input to 3-D models and expect reasonable simulation results. This is because of the many uncertainties and significant differences in those input parameters with respect to their spatial and temporal scales of measurements. Without further calibration, those parameters observed or determined on one spatial scale are in general inappropriate for use in different scale models.

Calibrations of the mountain-scale UZ flow model rely on field-measured matrixliquid saturation, water-potential, perched-water, and chloride data to adjust 3-D model parameters through a series of 3-D model calibrations (Wu et al., 2003). The calibrated parameters include fracture-matrix properties of the TSw layers, the PTn unit, and perched-water zones. 
The 3-D flow model calibration (Wu et al., 2003) presents three sets of parameters, corresponding to the low, mean, and upper bounds of present-day infiltration rates. Specifically, the three sets of parameters calibrated by the 3-D model (Wu et al., 2003) are used in this work as base-case (Case A) model input parameters, while the three sets of the 1-D model calibrated properties (Liu et al., 2003b) are employed as alternative parameter sets (or Case B) for comparison and sensitivity analyses. The difference between the three base-case (Case A) and three alternative (Case B) parameter sets is in PTn properties only, of which the base-case has a narrower range of permeability values than that of the alternative case. The classification of base-case and alternative parameters is based on model calibration results, because base-case input parameters provide an overall better match to field data (Wu et al., 2003) than those obtained using the alternative sets.

\section{Comparisons with Saturation, Water-Potential and Perched-Water Data}

Measured matrix liquid saturation, water-potential data, and perched-water elevations from all sampling boreholes have been compared to 3-D model results. This has resulted in model-parameter adjustments in several TSw model layers and perchedwater zones. Simulated and observed matrix liquid saturations and water potentials along the vertical column for borehole SD-12 are compared in Figures 3 and 4, respectively, for the three present-day infiltration rates. In general, the modeled results from all simulations after calibration are in reasonable agreement with the measured saturation and water-potential profiles, as well as perched water levels.

\section{Comparison with Chloride Data}

Estimating percolation flux is one of the main objectives of the UZ modeling studies. Water percolation and infiltration history may be revealed by study of chemically 
based natural tracers as observed in the UZ (Liu et al., 2003c). Among those commonly used natural tracers, chloride is ideal for study of UZ percolation behavior and patterns. This is because chloride is very closely associated with past and current water movement and at the same time is chemically inert. Therefore, this work uses chloride data measured from an underground tunnel, the Exploratory Studies Facilities (ESF) (Fabryka-Martin et al., 2002), and from borehole SD-9 to examine UZ percolation behavior.

In our study, chloride transport analyses are carried out using the same 3-D UZ flow model grid (Figure 1) and the same dual-continuum modeling approach for handling fracture-matrix interaction. The chloride transport simulations are performed using the T2R3D code with spatially varying chloride recharge on the surface and run for 100,000 years to approximate the current, steady-state conditions under the infiltration scenarios considered. Chloride is treated as a conservative component transported through the UZ, subject to advection and diffusion processes. Note that the T2R3D code is designed to simulate radionuclide transport processes in porous or fractured media, with full incorporation of the 3-D hydrodynamic dispersion tensor on irregular 3-D integral-finite difference grids (Wu and Pruess, 2000). In this study, however, the mechanical dispersion effect through the fracture-matrix system is ignored, because sensitivity studies have indicated that mechanical dispersion has an insignificant effect (Wu et al., 2002a). A constant molecular diffusion coefficient of $2.032 \times 10^{-9} \mathrm{~m}^{2} / \mathrm{s}$ is used for $\mathrm{Cl}$.

Six present-day, steady-state UZ flow fields, preq_lA, preq_lB, preq_mA, preq_mB, preq_uA, and preq_uB of Table 1, are incorporated within the transport modeling, i.e., each of the three present-day infiltration scenarios is associated with either one of two sets (base-case and alternative parameters) of the PTn properties. Six chloride transport simulation results, using the two PTn parameter sets under the three present-day 
infiltration scenarios, are compared to measured chloride data. Pore-water chloride concentrations simulated with the six different flow scenarios and their comparisons with measurements are plotted in Figure 5. Figure 5a shows the difference between measurements and 3-D model simulated results along the ESF, while Figure 5b presents the differences for Borehole SD-9.

Figure 5a indicates that measured chloride data along the ESF are clustered around three areas with distances of about 1,000, 3,600, and 6,600-7,500 $\mathrm{m}$ from the northern portal of the tunnel. As shown in Figure 5a, the two simulation results with the present-day, lower-bound infiltration (preq_1A and preq_lB) cannot in general match the observed results. For the first two locations, at 1,000 and 3,600 m, the simulated results from the two PTn conceptual models and the mean and upper-bound infiltration are all in good agreement with the measurements. However, for the last portion from $6,600-7,5000$ $\mathrm{m}$, the simulations with the base-case models (preq_mA or preq_uA) are in slightly better agreement with the measured chloride concentrations. A similar comparison is also shown in Figure 5b at borehole SD-9, and the base-case model results with preq_mA or preq_uA provide the best matches.

In addition to comparisons made with ESF and borehole SD-9 data, more comparative studies of chloride distributions, using data from other boreholes and tunnels within the UZ, have been conducted for analyzing simulation results using the base-case and alternative model parameters (Wu et al., 2003). These studies consistently indicate that simulation results using the base-case flow fields with the present-day, mean infiltration provide an overall better match with the observed chloride data than the alternative model results. This is because the base-case flow fields in general predict relatively large lateral diversion (Wu et al., 2002b). Note that, as discussed above (in the Model Calibration section), the only difference between the base-case and alternative 
flow fields is the use of different PTn properties, with the base case having generally less variable permeability among the PTn layers than the alternative case. The comparison of model results and measured chloride data (Figures 5a and 5b) shows that the simulation results with the base-case flow fields are in overall better agreement with the measurements than those from the alternative flow fields with smaller lateral flow. This indicates that large lateral diversion may occur in percolation fluxes throughout the PTn unit, which has a direct impact on chloride transport and distributions. In addition, these results also indicate that surface infiltration should be higher than the present-day, lowerbound scenario, since simulation results with low infiltration rates cannot in general match observation results.

\section{FLOW PATTERNS AND ANALYSES}

A total of 18 steady-state flow simulation scenarios are studied in this work, as listed in Table 1, with 9 base cases and 9 alternatives. The difference between the basecase and alternative scenarios is the implementation of different PTn properties, i.e., using two different PTn conceptual models (Wu et al., 2003). The objectives of investigating 18 3-D flow scenarios is to cover various uncertainties and possibilities for UZ flow patterns under current and future climates, as well as different conceptual models. Percolation flux through the UZ is considered one of the most critical factors affecting potential repository performance, because of its direct impact on radionuclide mobilization from repository drifts. Furthermore, because percolation fluxes of unsaturated flow cannot be readily measured in the field, they have to be estimated using flow models.

\section{Percolation Flux at Repository}

Figure 6 shows an example of percolation fluxes simulated at the repository level 
for the present-day climate. In this analysis, the percolation flux is defined as total vertical liquid mass flux through both fractures and matrix, and is converted to millimeters per year $(\mathrm{mm} / \mathrm{yr})$ using a constant water density. Comparisons of the calculated repository percolation fluxes with those of the surface infiltration maps (e.g., Figure 6 versus Figure 2) indicate that percolation fluxes at the repository are very different from surface infiltration patterns. The major differences in percolation flux at the repository level (Figure 6) from the surface infiltration (Figure 2) are two fold: (1) significant flow is diverted into or near faults and (2) there is a $500 \mathrm{~m}$ eastward movement of the high infiltration zones (denoted by dark "green" areas) on the surface and repository horizon in the center of the model domain without faults (Figure 2 versus Figure 6). This indicates significant eastward lateral flow occurrence when traveling from surface to repository level. Note also that surface infiltration rates and distributions, as shown in Figure 2, are independent of faults. Moreover, flow redistribution in the very northern part of the model domain (far beyond the repository block) results from the local low-permeability $\mathrm{CHn}$ zeolitic and perched-water zones, which have higher elevations in the north and intersect the repository horizon grid layer. Therefore, major flow paths develop along the faults in the very northern part of the model domain.

Overall, simulated percolation fluxes from the base-case model results, as shown in Figure 6, display very different patterns from the surface infiltration maps, whereas the alternative model results show relatively small differences ( $\mathrm{Wu}$ et al., 2003). This indicates that with the base-case model simulation results, more large-scale lateral flow occurs when the percolation flux crosses the PTn unit.

\section{Flux Frequency Distribution}

Percolation fluxes within the repository footprint can be further analyzed using a frequency distribution plot. This plot displays the average area percentage of the 
repository region subject to a particular percolation rate. Note that the normalized flux rates are determined by normalizing an infiltration value with respect to the average infiltration rate for the scenario. For example, 1 for the normalized flux rate corresponds to $4.4,11.8$, and $17.0 \mathrm{~mm} / \mathrm{yr}$ (Table 1), respectively, for the three mean infiltration scenarios. Figure 7 indicates that the highest flux frequencies have a normalized flux of about 0.5 or less and occur over about $50 \%$ of the repository area. The area with normalized percolation fluxes greater than 5 comprises less than $1 \%$ of the total repository area. In general, modeling results for all of the 18 flow fields show that the percolation flux value with highest areal distribution frequencies is always lower than the average values of the corresponding infiltration rates.

Flux frequency distributions, as shown in Figure 7, provide probability functions for occurrence of a particular range of percolation fluxes at the repository level with each UZ flow field. This information can be used as the ambient flux boundary conditions for drift-scale and seepage models of flow simulations at repository drifts (Bodvarsson et al., 2003).

\section{Groundwater Travel Times}

Tracer-transport simulation results can also provide insight into flow patterns for groundwater travel or radionuclide-transport times below the repository. Groundwater travel or radionuclide-transport times are here estimated by conservative (nonsorbing) and reactive (sorbing), nondecaying tracer simulations, in which tracers are tracked after release from the repository fractures and transported to the water table. Similarly to the modeling studies of chloride transport described above, simulation results and analyses of groundwater travel times are based on transport modeling of conservative and reactive tracers using the T2R3D code and the UZ flow model grid of Figure 1. The total of 18 
steady-state, 3-D flow fields of the base case infiltration scenarios (Table 1) are directly input to the T2R3D code for modeling transport of the conservative and reactive tracers from the repository to the water table, resulting in a total of 36 simulation scenarios.

In transport modeling, an initial, constant-source concentration, specified for the fracture continuum gridblocks representing the repository (Figure 1a), was released at the starting time of the simulation. In selecting transport properties, mechanical dispersion through the fracture-matrix system was ignored for the same reason discussed in the previous section regarding chloride transport. In addition, molecular diffusion coefficients and $K_{d}$ values were chosen to represent two radionuclides, technetium (Tc) and neptunium (Np), respectively (Wu et al., 2002a).

Tracer and radionuclide transport times (since release from the proposed repository, through the $\mathrm{CHn}$, to the water table) may be analyzed using statistics of $50 \%$ mass breakthrough times for tracer or radionuclide at the water table. Figure 8 correlates average infiltration rates and for tracer or radionuclide transport times at $50 \%$ mass breakthrough for the 36 simulation scenarios of tracer release into fractures at the repository. The statistical data of Figure 8 show the following:

- Groundwater travel times are inversely proportional to the average surface infiltration (net water recharge) rate. When an average infiltration rate increases from 5 to $35 \mathrm{~mm} / \mathrm{yr}$, average groundwater travel times (50\% breakthrough) decrease by more than one order of magnitude for both sorbing and nonsorbing species.

- Nonsorbing tracers migrate one to two orders of magnitude faster than sorbing tracers when traveling from the proposed repository to the water table, under the same infiltration conditions. Therefore, adsorption onto rock solids, mainly in the 
CHn unit, appears to have a significant impact on transport times of adsorbing tracer/radionuclide.

\section{SUMMARY AND CONCLUSIONS}

This paper presents an updated 3-D mountain-scale UZ flow model developed for characterizing fluid flow and tracer/radionuclide transport in the UZ of Yucca Mountain. As a continuing effort, the UZ flow model has been calibrated using available data measured at the site, including field-measured saturation, water-potential, perched-water, and pore-water chloride data. These model-calibration efforts enable us to conclude that the model can be used to estimate the current ambient moisture conditions in the Yucca Mountain UZ system, such as matrix liquid saturation, water potential, and perched water occurrence.

The model results indicate that percolation patterns at the repository horizon are very different from surface infiltration fluxes. These differences are caused by lateral flow or diversion and flow focusing into faults, which occur as water travels through the PTn unit. The modeling analysis using field measured chloride data reveals the occurrence of large-scale lateral flow within the PTn unit. In addition, tracer-transport studies indicate that there exists a wide range of simulated groundwater travel or tracertransport times from the repository to the water table, associated mainly with different infiltration rates and modeling scenarios. Sensitivity analyses indicate that surface infiltration rates and adsorption effects in the $\mathrm{CHn}$ unit are the most important factors for determining tracer-transport times. 


\section{ACKNOWLEDGMENTS}

We would like to thank Guoxiang Zhang and Dan Hawkes for their review of this paper. We would also like to thank the associate editor and the two anonymous reviewers for their critical, insightful, and constructive comments and suggestions for improving the manuscript. In addition, we are grateful to Lehua Pan, H. H. Liu, and Diana Swantek for their help to this work. This work was in part supported by the Director, Office of Civilian Radioactive Waste Management, U.S. Department of Energy, through Memorandum Purchase Order EA9013MC5X between Bechtel SAIC Company, LLC and the Ernest Orlando Lawrence Berkeley National Laboratory (Berkeley Lab). The support is provided to Berkeley Lab through the U.S. Department of Energy Contract No. DE-AC03-76SF00098

\section{REFERENCES}

Ahlers, C. F., S. Finsterle, and G. S. Bodvarsson, 1999. Characterization and Prediction of Subsurface Pneumatic Response of at Yucca Mountain, Nevada, Journal of Contaminant Hydrology, 38 (1-3), pp.47-68.

Ahlers, C.F., T. M. Bandurraga, G. S. Bodvarsson, G. Chen, S. Finsterle, and Y. S. Wu, 1995. Summary of Model Calibration and Sensitivity Studies Using the LBNL/USGS Three-Dimensional Unsaturated Zone Site-Scale Model, Yucca Mountain Site Characterization Project Report. Milestone 3GLM107M, Berkeley, California: Lawrence Berkeley National Laboratory.

Bandurraga, T. M. and G. S. Bodvarsson, 1999. Calibrating Hydrogeologic Properties for the 3-D Site-Scale Unsaturated Zone Model of Yucca Mountain, Nevada, Journal of Contaminant Hydrology, 38 (1-3), pp.5-46.

Bodvarsson, G. S., Y. S. Wu and K. Zhang, 2003. Development of Discrete Flow Paths in Unsaturated Fractures at Yucca Mountain, LBNL-49863, Journal of Contaminant Hydrology, Vol. 62-63, pp. 23-42.

Buesch, D. C., R. W. Spengler, P. H. Nelson, D. T. Vaniman, S. J. Chipera, and D. L. Bish, 1995. Geometry of the Vitric-Zeolitic Transition in Tuffs and the Relation to Fault Zones at Yucca Mountain, Nevada, International Union of Geodesy and Geophysics, XXI General Assembly, July 2-14, 1995, A426.

Fabryka-Martin, J., A. Meijer, B. Marshal, L. Neymark, J. Paces, J. Whelan, and A. Yang, 2002. Analysis of Geochemical Data for the Unsaturated Zone, Report ANL-NBSHS-000017, Los Alamos, NM, Los Alamos National Laboratory, Las Vegas, Nevada, CRWMS M\&O. 
Hevesi, J. and L. Flint, 2000. Simulation of Net Infiltration for Modern and Potential Future Climate. Report ANL-NBS-GS-000008, Denver, Colorado: U. S. Geological Survey.

Liu, H. H., C. F. Ahlers, L. Pan, and Y. S. Wu, 2003a. Analysis of Hydrologic Properties Data, Research Report: MDL-NBS-HS-000014, REV00, Lawrence Berkeley National Laboratory, Las Vegas, Nevada, CRWMS M\&O.

Liu, H. H., C. F. Ahlers, S. Mukhpadhayay, and Y. S. Wu, 2003b. Calibrated Properties Model, Report: MDL-NBS-HS-000003, REV01, Lawrence Berkeley National laboratory, Las Vegas, Nevada, CRWMS M\&O.

Liu, J., E. L. Sonnenthal, and G. S. Bodvarsson, 2003c. Calibration of Yucca Mountain Unsaturated Zone Flow and Transport Model Using Porewater Chloride Data, Journal of Contaminant Hydrology, Vol. 62-63, pp.213-235.

Liu, H. H., C. Doughty, C., and G. S. Bodvarsson, 1998. An Active Fracture Model for Unsaturated Flow and Transport in Fractured Rocks, Water Resource Research, v. 34, pp.2633-2646.

Montazer, P. and W. E. Wilson, 1984. Conceptual Hydrologic Model of Flow in the Unsaturated Zone, Yucca Mountain, Nevada, Water-Resources Investigations Report 844345, Lakewood, Colorado, the U. S. Geological Survey.

Pruess, K., 1991. TOUGH2-A General-Purpose Numerical Simulator for Multiphase Fluid and Heat Flow, LBL-29400, Berkeley, California, Lawrence Berkeley Laboratory.

Robinson, B. A., C. Li, and C. K. Ho, 2003. Performance assessment model development and analysis of radionuclide transport in the unsaturated zone, Yucca Mountain, Nevada, Journal of Contaminant Hydrology, 62-63, pp. 249-268.

Rulon, J., G. S. Bodvarsson, P. Montazer, 1986. Preliminary Numerical Simulations of Groundwater Flow in the Unsaturated Zone, Yucca Mountain, Nevada, LBL-20553. Berkeley, California, Lawrence Berkeley Laboratory.

Scott, R. B. and J. Bonk, 1984. Preliminary Geologic Map of Yucca Mountain, Nye County, Nevada, with Geologic Sections, Open-File Report 84-494, Denver, Colorado, the U. S. Geological Survey.

Tsang, Y. W. and K. Pruess, 1987. A Study of Thermally Induced Convection near a High-Level Nuclear Waste Repository in Partially Saturated Fracture Tuff, Water Resources Research, 23(10), pp.1958-1966.

van Genuchten, M. Th., 1980. A Closed-Form Equation for Predicting the Hydraulic Conductivity of Unsaturated Soils, Soil Sci. Soc. Amer. J., 44(5), pp. 892-898.

Viswanathan, H. S., B. A. Robinson, A. J. Valocchi, and I. R. Triay, 1998. A Reactive Transport Model of Neptunium Migration from the Potential Repository at Yucca Mountain, Journal of Hydrology, 209, pp. 251-280. 
Wittwer, C., G. Chen, G. S. Bodvarsson, M. Chornack, A. Flint, L. Flint, E. Kwicklis, and R. Spengler, 1995. Preliminary Development of the LBL/USGS Three-Dimensional Site-Scale Model of Yucca Mountain, Nevada, LBL-37356, Berkeley, California, Lawrence Berkeley Laboratory.

Wittwer, C. S. G. S. Bodvarsson, M. P. Chornack, A. Flint, L. Flint, B. D. Lewis, R. W. Spengler, and C. A. Rautman, 1992. Design of a Three-Dimensional Site-Scale Model for the Unsaturated Zone at Yucca Mountain, Nevada, High Level Radioactive Waste Management, Proceedings of the Third International Conference, Las Vegas, Nevada, April 12-16, 1992. 1, pp.263-271.

Wu, Y. S., G. Lu, K. Zhang, G. Zhang, G., H. Liu, T. Xu, and E. Sonnenthal, 2003. UZ Flow Models and Submodels, MDL-NBS-HS-000006 REV 01, Las Vegas, Nevada, Bechtel SAIC Company.

Wu, Y. S., L. Pan, W. Zhang, and G. S. Bodvarsson, 2002a. Characterization of Flow and Transport Processes within the Unsaturated Zone of Yucca Mountain, Nevada. Journal of Contaminant Hydrology 54, pp. 215-247.

Wu, Y. S., W. Zhang, L. Pan, J. Hinds, and G. S. Bodvarsson, 2002b. Modeling capillary barriers in unsaturated fractured rock, Water Resources Research, 38 (11), pp. 35-1-3511.

Wu, Y. S. and K. Pruess, 2000. Numerical Simulation of Non-Isothermal Multiphase Tracer Transport in Heterogeneous Fractured Porous Media, Advances in Water Resources, Vol. 23, pp. 699-723.

Wu, Y. S, C. Haukwa, and G. S. Bodvarsson, 1999a. A Site-Scale Model for Fluid and Heat Flow in the Unsaturated Zone of Yucca Mountain, Nevada. Journal of Contaminant Hydrology. 38 (1-3), pp.185-217.

Wu, Y. S., A. C. Ritcey, and G. S. Bodvarsson, 1999b. A Modeling Study of Perched Water Phenomena in the Unsaturated Zone at Yucca Mountain. Journal of Contaminant Hydrology. 38 (1-3), pp.157-184.

Wu, Y. S., A. C. Ritcey, C. Haukwa, and G. S. Bodvarsson, 1997. Integrated 3-D SiteScale Flow Model, Chapter 19 of "The Site-Scale Unsaturated Zone Model of Yucca Mountain, Nevada, for the Viability Assessment" Edited by G. S. Bodvarsson, M. Bandurraga and Y. S. Wu, Yucca Mountain Site Characterization Project Report, LBNL40376, UC-814, Lawrence Berkeley National Laboratory, Berkeley, CA.

\section{List of Figures Captions}

Figure 1a. Plan view of the 3-D UZ flow model grid, showing the model domain, faults incorporated, proposed repository layout, and several borehole locations. 
Figure 1b. Vertical view along an east-west cross section (W-E of Figure 1a) of the 3-D UZ flow model grid, showing vertical grid layers, hydrogeological units, faults, proposed repository section, and surface and water table boundaries.

Figure 1c. Vertical view along a north-south cross section (N-S of Figure 1a) of the 3-D UZ flow model grid, showing vertical grid layers, hydrogeological units, faults, proposed repository section, and surface and water table boundaries

Figure 2. $\quad$ Plan view of net infiltration distributed over the 3-D UZ flow model grid for the base-case, or present-day, mean infiltration scenario.

Figure 3. Comparison of simulated and observed matrix liquid saturations and perched-water elevations for borehole SD-12, using the results of the simulations for base case present-day infiltration of mean, lower, and upper bounds.

Figure 4. Comparison to simulated and observed water potentials and perched-water elevations for borehole SD-12, using the results of the simulations for base case present-day infiltration of mean, lower, and upper bounds.

Figure 5a. Comparison of simulated and observed chloride concentration (mg/L) profiles along the ESF for present infiltration with mean, upper, and lower bounds with six flow fields (preq_uA, preq_mA, preq_1A, preq_uB, preq_mB, and preq_1B).

Figure 5b. Comparison between measured and simulated chloride concentration (mg/L) profiles at borehole SD-9 for present infiltration with mean, upper, and lower bounds with six flow fields (preq_uA, preq_mA, preq_1A, preq_uB, preq_mB, and preq_lB).

Figure 6. Simulated percolation fluxes at the proposed repository horizon for base case present-day, mean infiltration using the results of simulation preq_mA.

Figure 7. Areal distribution frequency of simulated base-case percolation fluxes within the proposed repository domain, normalized to the three mean infiltration rates: (a) present day; (b) monsoon; and (c) glacial transition.

Figure 8. Correlation of average infiltration rates and base case groundwater travel or tracer transport times at $50 \%$ mass breakthrough for the 36 simulation scenarios for technetium (Tc) and neptunium (Np).

Table 1. Infiltration Rates (mm/year) Averaged over the Model Domain and Simulation Scenarios of Base Cases and Alternatives 


\begin{tabular}{|c|c|c|c|c|}
\hline \multicolumn{2}{|c|}{ Rate/Scenario } & Lower-Bound & Mean & Upper-Bound \\
\hline \multirow[b]{2}{*}{ Present-Day } & Rate & 1.3 & 4.4 & 10.7 \\
\hline & Scenario & preq_1A \& preq_1B" & preq_mA \& preq_mB & preq_uA \& preq_uB \\
\hline \multirow[b]{2}{*}{ Monsoon } & Rate & 4.4 & 11.8 & 19.2 \\
\hline & Scenario & monq_1A \& monq_1B & monq_mA \& monq_mB & monq_uA \& monq_uB \\
\hline \multirow{2}{*}{$\begin{array}{c}\text { Glacial } \\
\text { Transition }\end{array}$} & Rate & 2.4 & 17.0 & 31.7 \\
\hline & \begin{tabular}{|l} 
Scenario \\
\end{tabular} & glaq_1A \& glaq_lB" & glaq_mA \& glaq_mB & glaq_uA \& glaq_uB \\
\hline \multicolumn{5}{|c|}{$\begin{array}{l}\text { *Here code names such as preq_1A and preq_lB are denoted for simulation case or scenario, with } \\
\text { preq, monq, and glaq representing, present-day, monsoon, and glacial transition, respectively; with } \\
\text { for lower, m for mean, u for upper bounds, respectively; A for the base case parameter model and } \\
\text { B for the alternative parameter model. }\end{array}$} \\
\hline
\end{tabular}



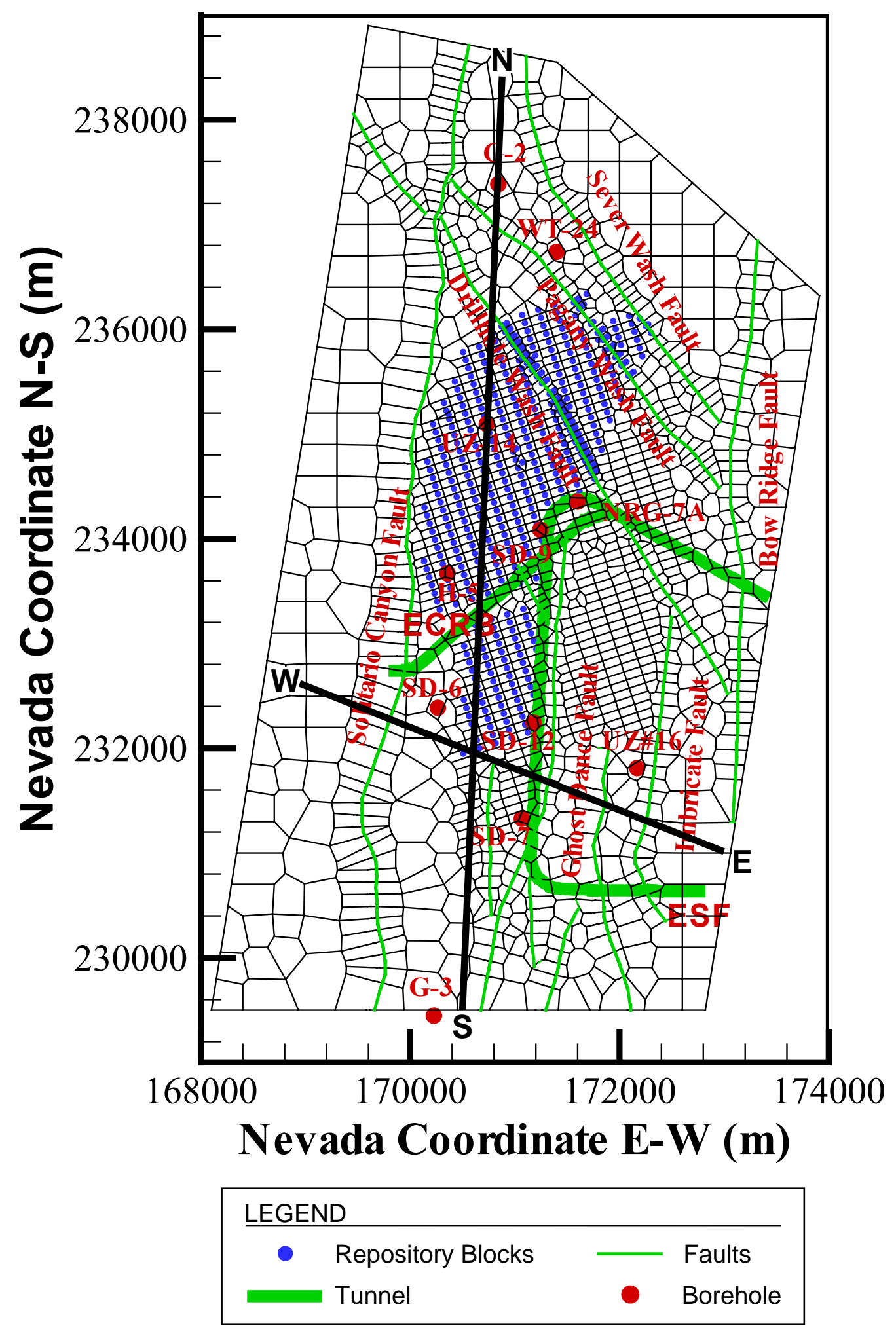

UZ04-007

Figure 1a. Plan view of the 3-D UZ flow model grid, showing the model domain, faults incorporated, proposed repository layout, and several borehole locations 


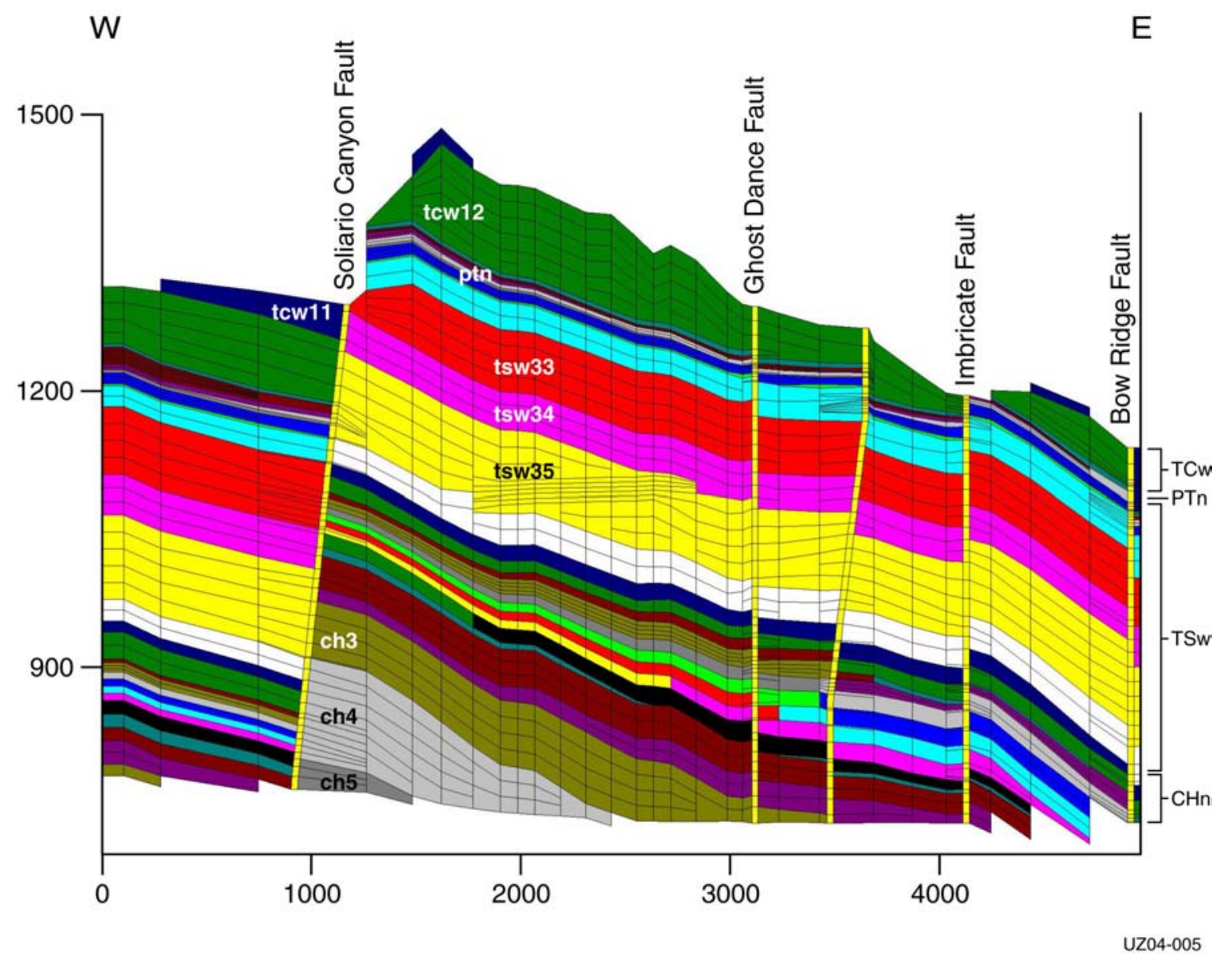

Figure 1b. Vertical view along an west-east cross section (W-E of Figure 1a) of the 3-D UZ flow model grid, showing vertical grid layers, hydrogeological units, faults, proposed repository section, and surface and water table boundaries 


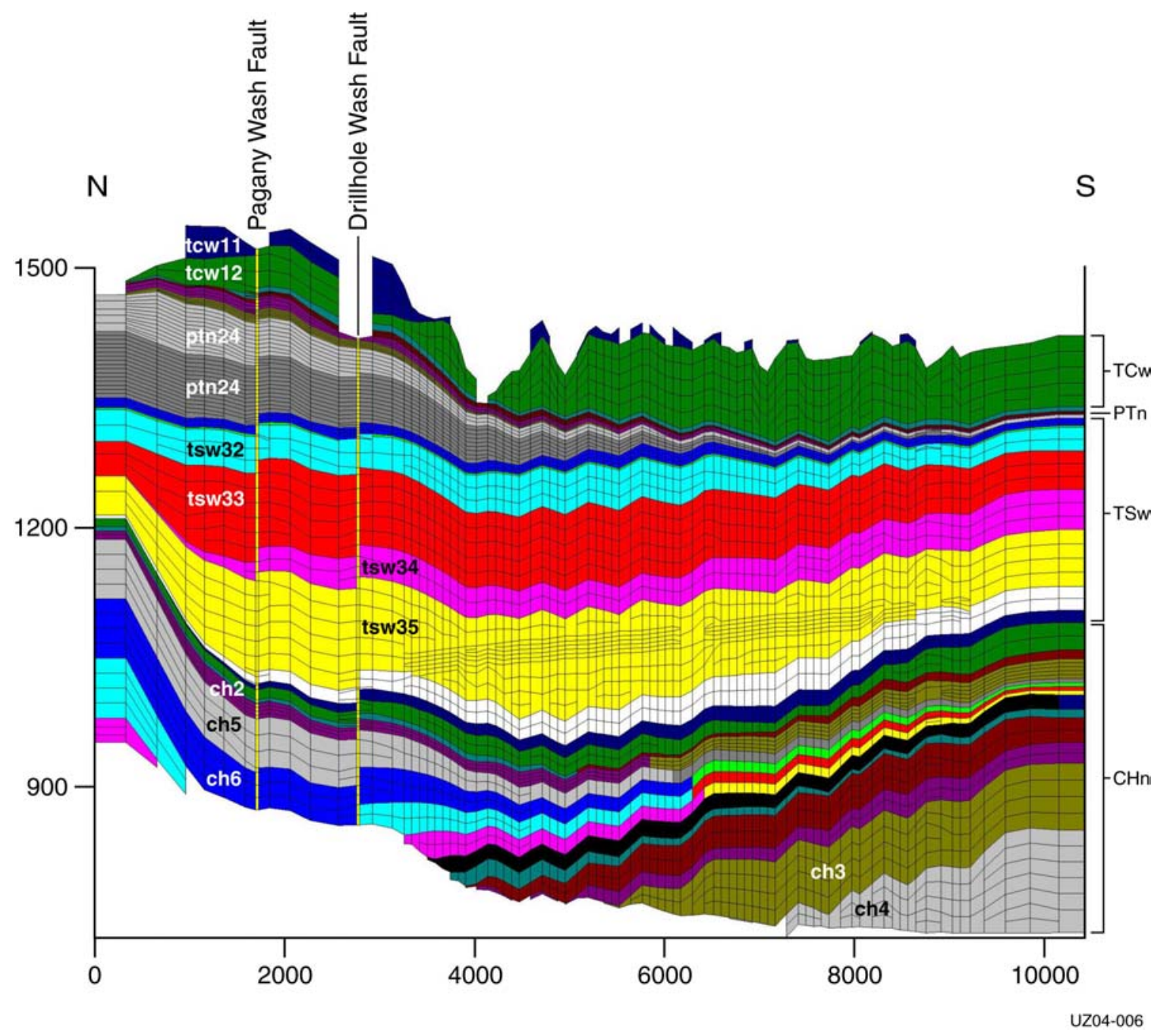

Figure 1c. Vertical view along a north-south cross section (N-S of Figure 1a) of the 3-D UZ flow model grid, showing vertical grid layers, hydrogeological units, faults, proposed repository section, and surface and water table boundaries 


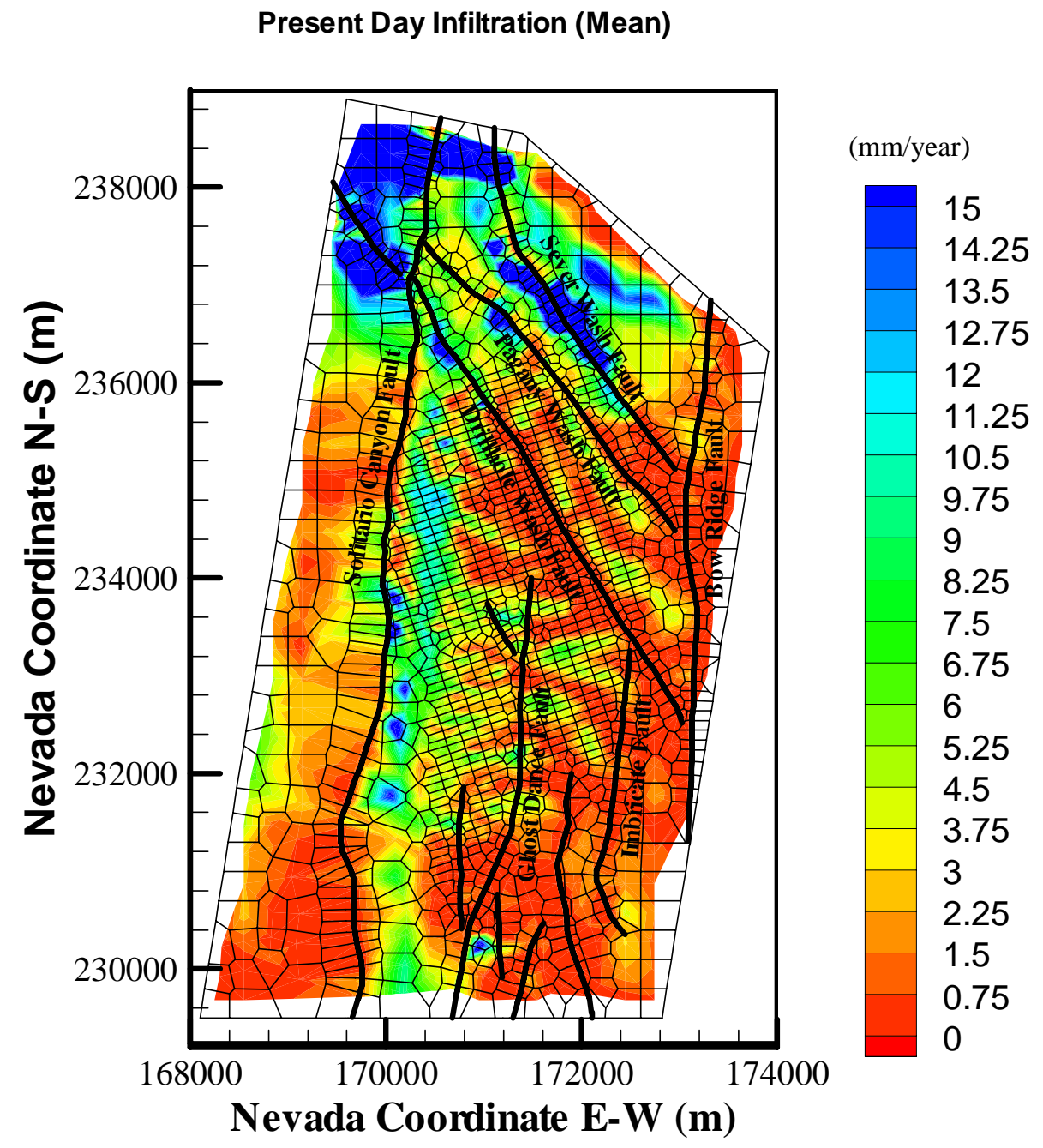

Figure 2. $\quad$ Plan view of net infiltration distributed over the 3-D UZ flow model grid for the base-case, or present-day, mean infiltration scenario. 


\section{SD-12}

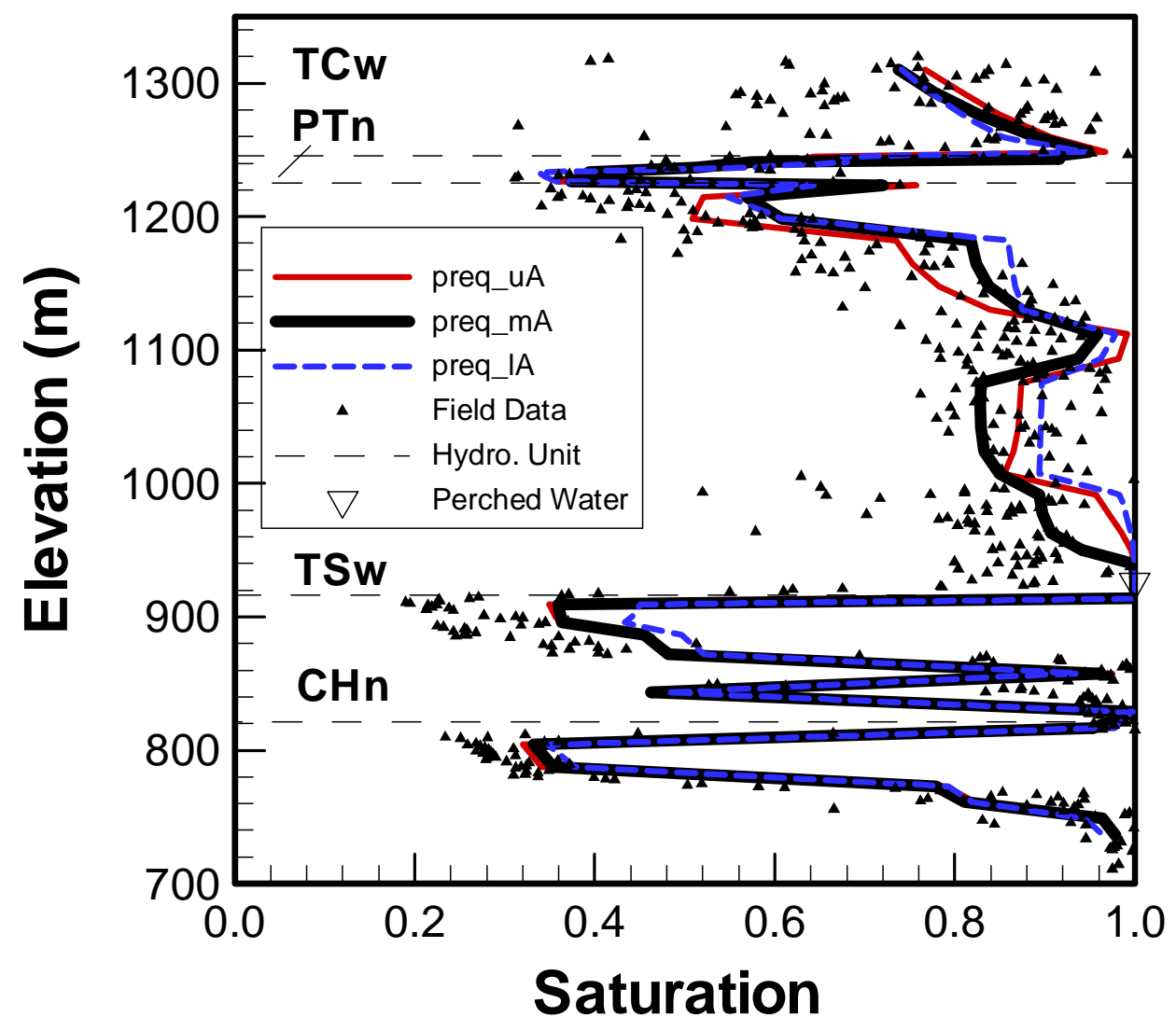

Figure 3. Comparison of simulated and observed matrix liquid saturations and perched-water elevations for borehole SD-12, using the results of the simulations for present-day infiltration of mean, lower, and upper bounds 


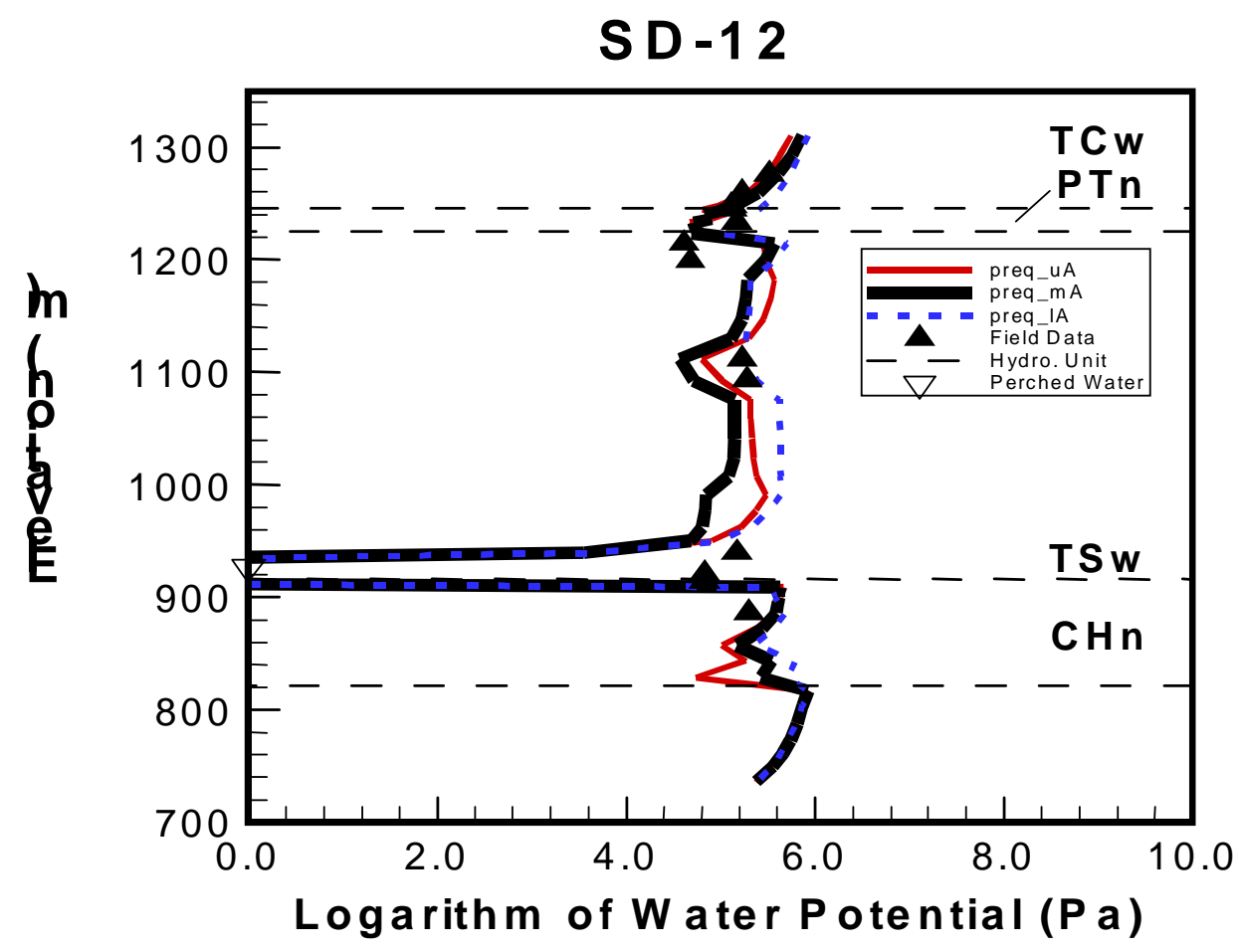

Figure 4. Comparison to simulated and observed water potentials and perched-water elevations for Borehole SD-12, using the results of the simulations for present-day infiltration of mean, lower, and upper bounds 


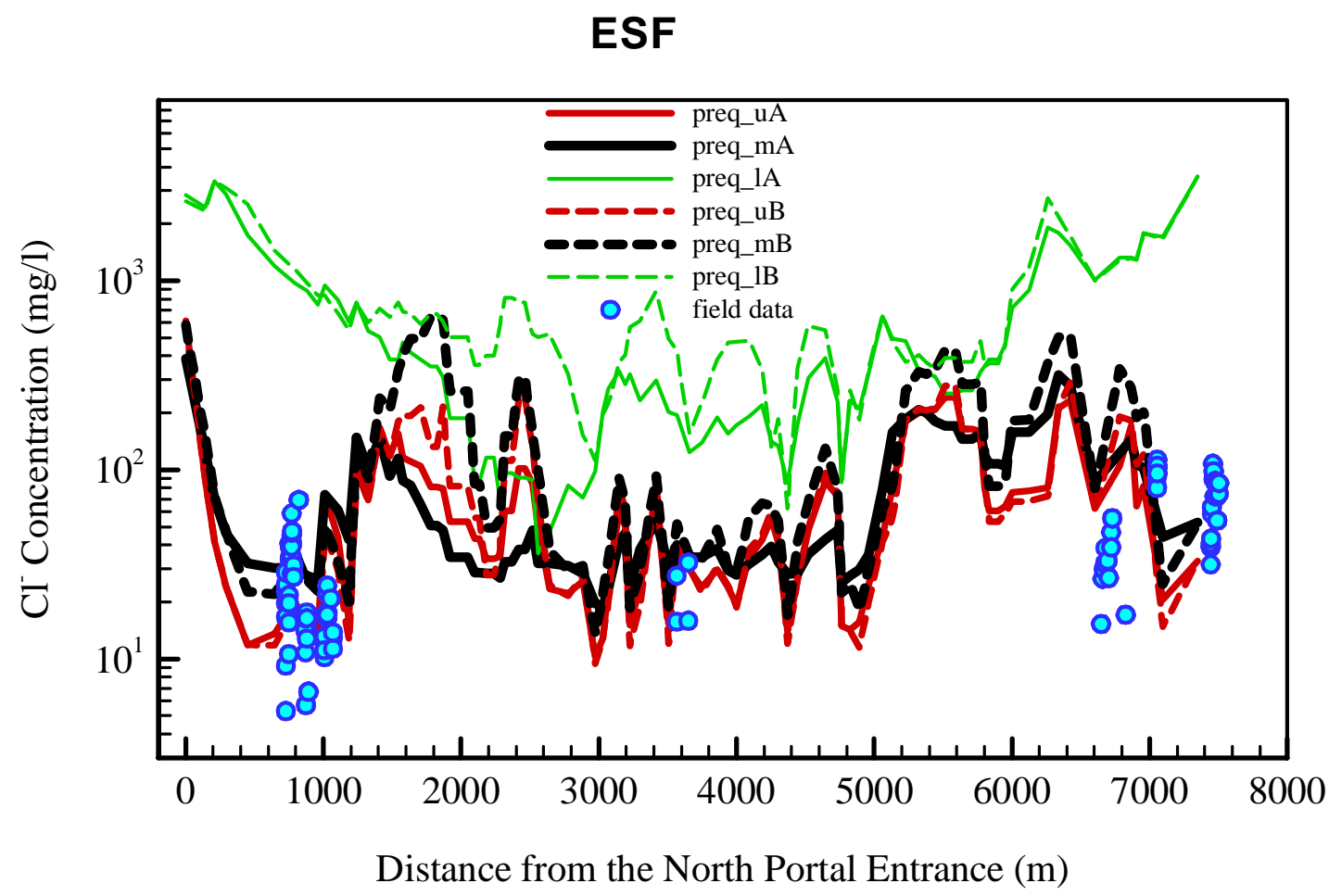

Figure 5a. Comparison of simulated and observed chloride concentration $(\mathrm{mg} / \mathrm{L})$ profiles along the ESF for present infiltration with mean, upper, and lower bounds with six flow fields (preq_uA, preq_mA, preq_1A, preq_uB, preq_mB, and preq_lB) 


\section{USW SD-9}

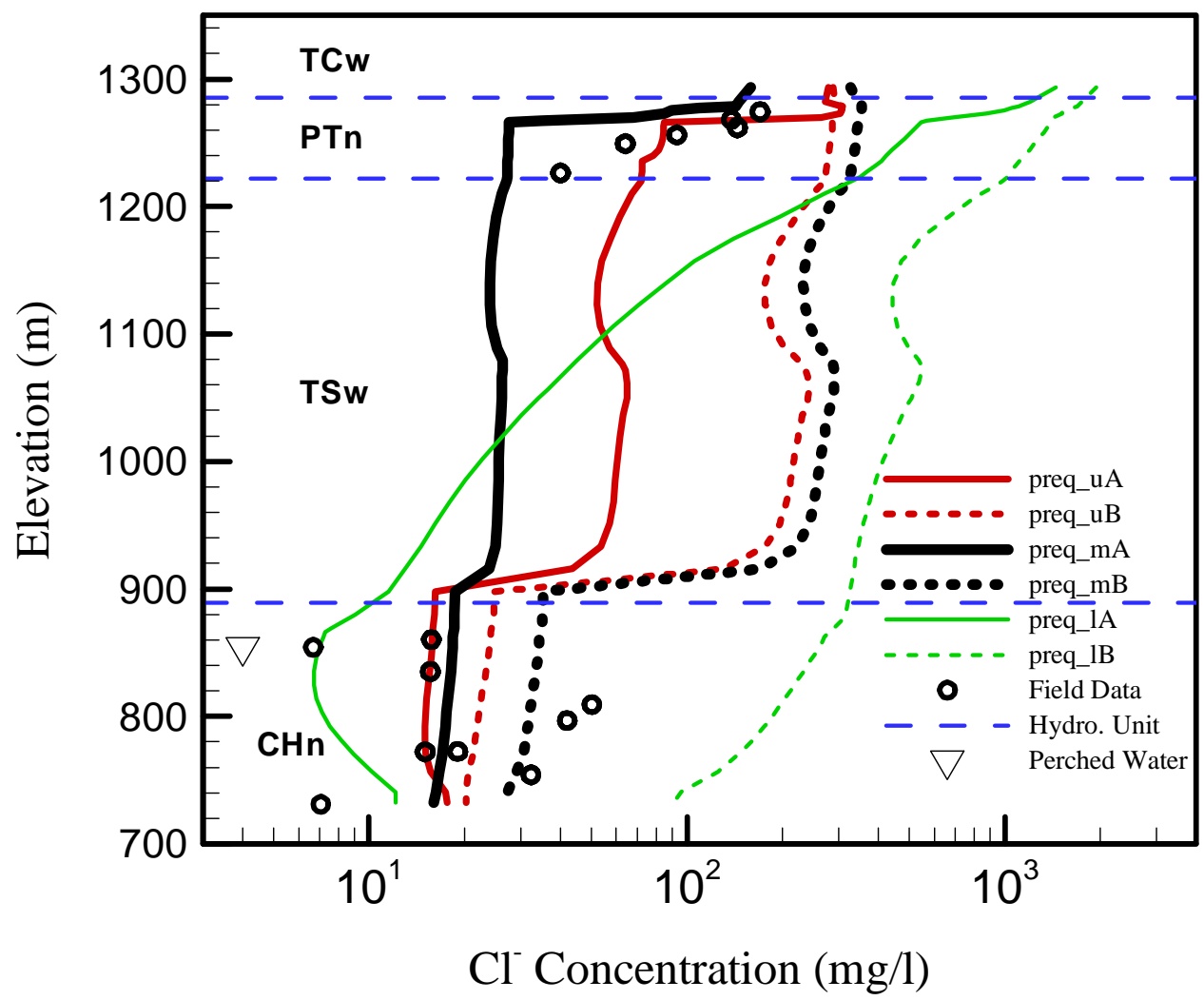

Figure 5b. Comparison between measured and simulated chloride concentration $(\mathrm{mg} / \mathrm{L})$ profiles at borehole SD-9 for present infiltration with mean, upper, and lower bounds with six flow fields (preq_uA, preq_mA, preq_1A, preq_uB, preq_mB, and preq_lB) 
vertical flux for preq_mA at repository layer

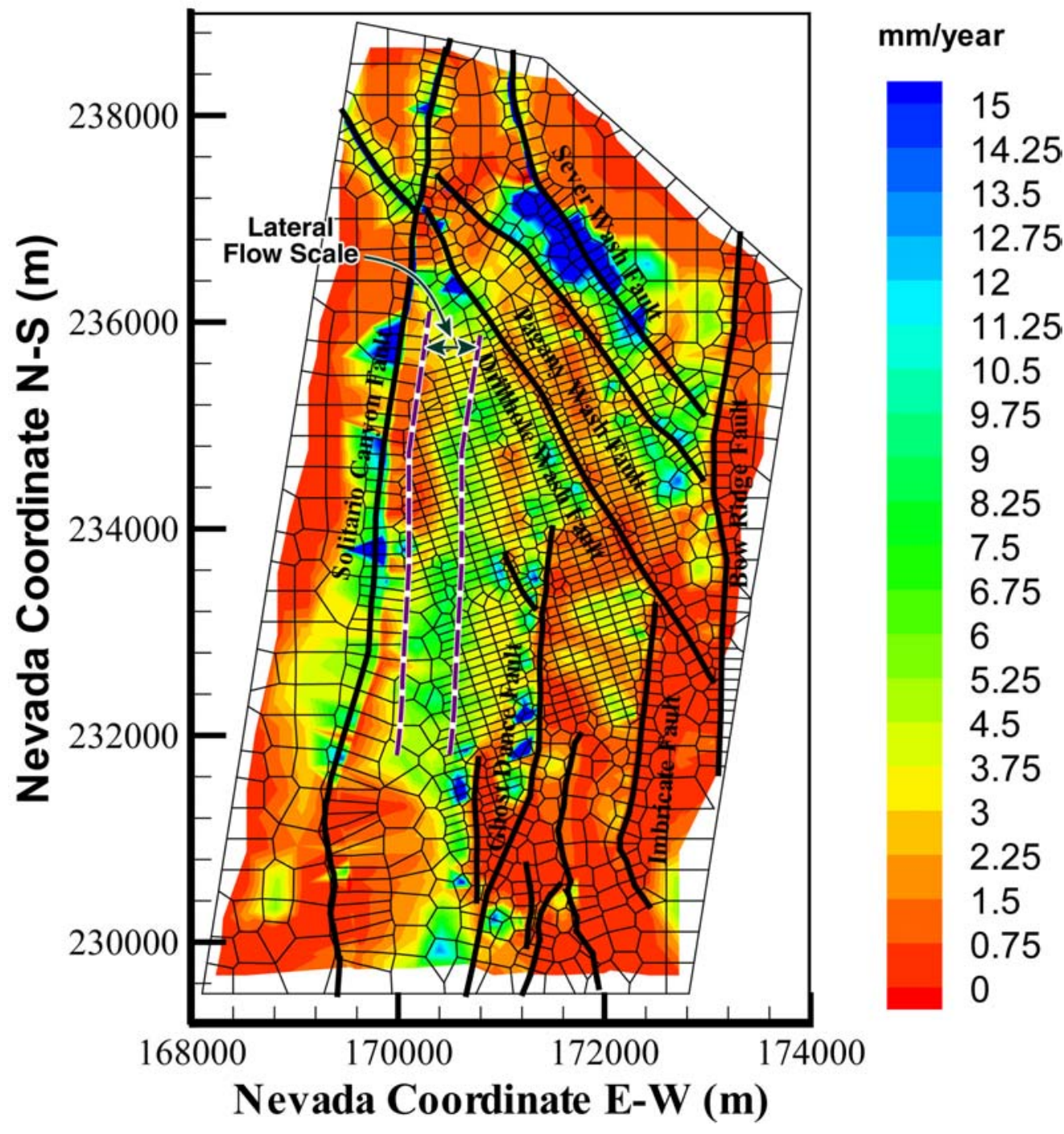

Figure 6. Simulated percolation fluxes at the proposed repository horizon under present-day, mean infiltration using the results of simulation preq_mA 


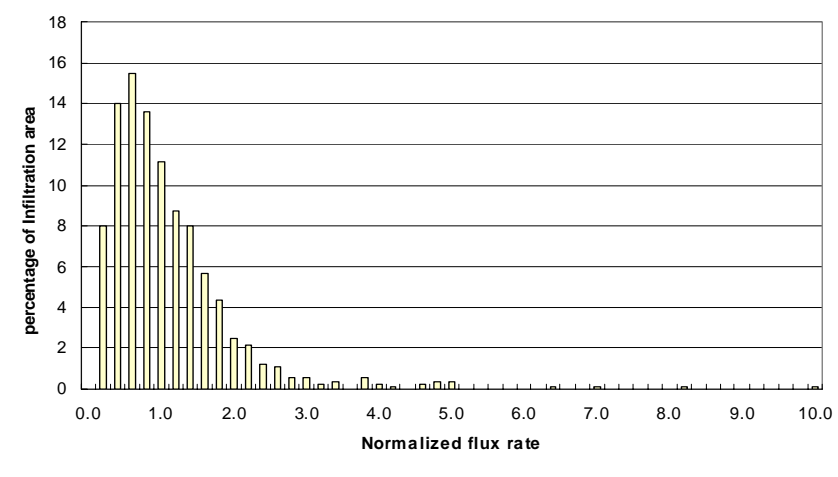

Monsoon, mean infiltration

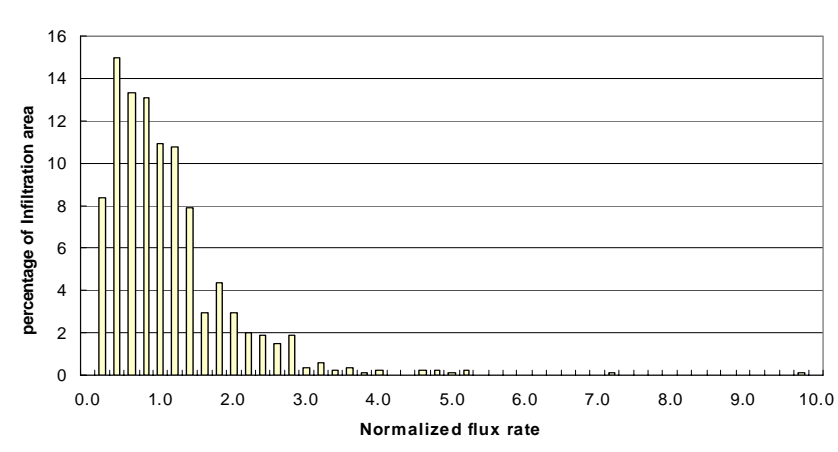

Glacial transition, mean infiltration

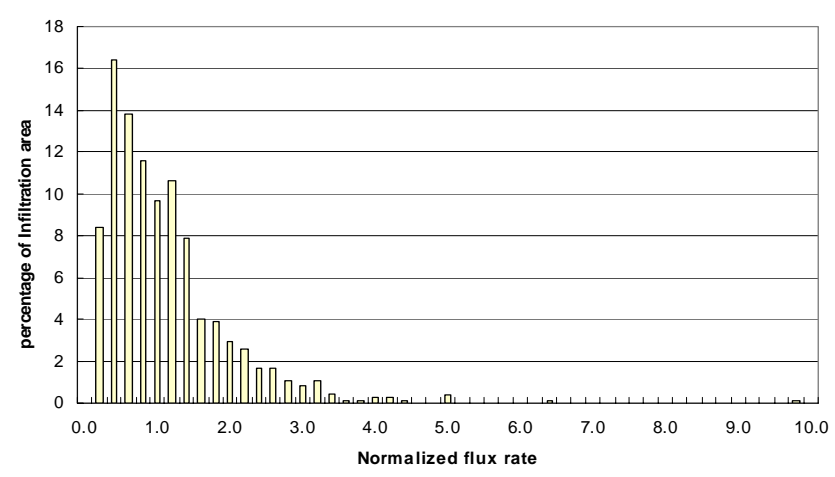

Figure 7. Areal frequency distribution of simulated percolation fluxes within the proposed repository domain, normalized to the three mean infiltration rates: (a) present day; (b) monsoon; and (c) glacial transition 


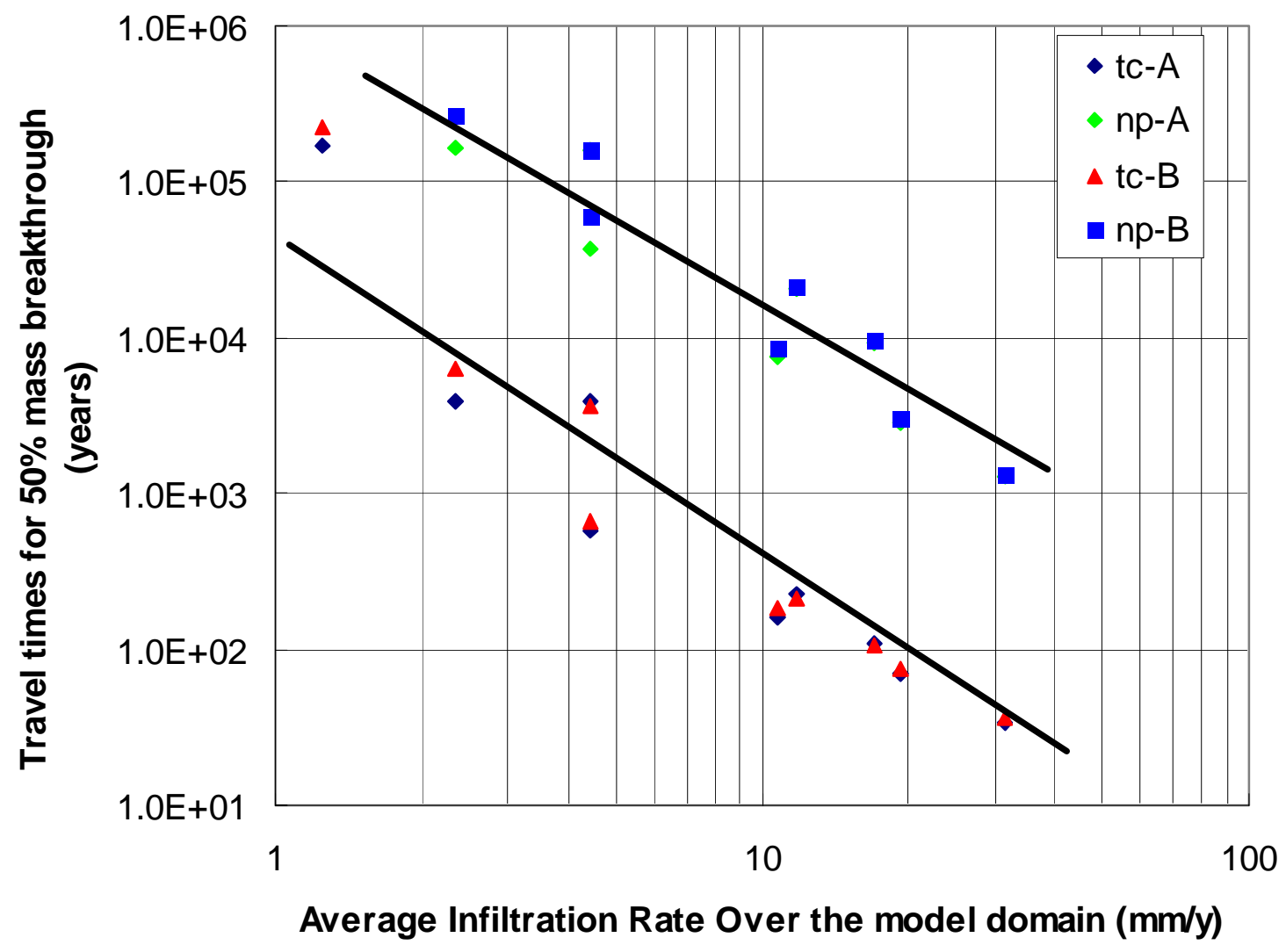

Figure 8. Correlation of average infiltration rates and groundwater travel or tracer transport times at $50 \%$ mass breakthrough for the 36 simulation scenarios 